\title{
PROGRAM-TARGET PLANNING AND MANAGEMENT THE CREATION OF COMPLEX TECHNICAL AND HUMAN-MACHINE SYSTEMS
}

\author{
Vitaly A. Barishpolets \\ Dorodnitsyn Computing Centre of the Russian Academy of Sciences, http://www.ccas.ru \\ 40, Vavilova str., Moscow 119333, Russian Federation \\ wcan@ccas.ru
}

Abstract. The paper reviews the development of methods of substantiation and selection of options when planning and management of human activities and development used in this process of technical means and organizational forms of planning and management. Provides the basic concepts of the program-target approach in planning and management of human activities. The main of these concepts is a program, the definition of which is given in the work. Discusses the basic principles of program-target planning and management the creation of complex technical and human-machine systems (CTS, HMS). Foremost among these principles is the end-to-end planning and management the creation of complex technical and human-machine systems life cycle. Describes the essence of decision making in end-to-end planning and management taking into account the uncertainties inherent in this process.

Keywords: planning, management, purpose, operation, program, mathematical model, uncertainties, decision making.

PACS: 89.75.Fb

Bibliographies - 9 references

Received 14 January 2014

RENSIT, 2014, 6(2):209-220

DOI: 10.17725/RENSITe.0006.201412e.0209

\section{Contents}

1. INTRODUCTION (209)

2. BASIC PRINCIPLES OF PROGRAM-TARGET PLANNING AND MANAGEMENT (210)

3. END-TO-END PLANNING AND MANAGEMENT OF THE CREATION OF CTS (HMS) (214)

4. Decision-making when END-To-end Planning AND MANAGEMENT OF THE CREATION OF CTS (HMS) (216)

5. ConClusion (220)

REFERENCES (220)

\section{INTRPDUCTION}

Planning and management of human activities in different branches took place at all times. That said methods of substantiation and selections of options of activities (decision making) have continuously developed, the technical means used in this process, as well as the formalization of organizational forms of planning and management.

In 1951 in the USA, the publisher of Massachusetts Institute of Technology published the first book in the world of Operations Research - Morse F.M., Kimball G.E. Methods of Operations Research. Cambridge, MA: Technology Press of MIT, New York, 1951, 158 p. In Russian language this book was published in the USSR in 1956. It described the statistical methods of assessment of efficiency of military operations with specific references and definition of quantitative basis for making the most effective decision by the leader of the military operation. Then the rapid development of operations research began in all developed countries. Currently Operations Research is a generalized name of the discipline, dealing with the development and application of mathematical methods, heuristic approaches and mathematical techniques to find optimal decisions in different branches of purposeful human activity. It includes: mathematical programming (linear, nonlinear, discrete, dynamic, stochastic); waiting theory; game theory; graph theory and mathematical methods of network planning; scheduling theory and combinatorial mathematics; inventory management, etc.

At the same time cybernetics as the science of control and communication in a living organism and machine began to explode (N. Wiener). At present, the objects of cybernetics are all managed systems. Each system is a plurality of interrelated elements able to perceive, remember and process information, and share it. Cybernetics studies the storage, transmission and processing of information, its use 
for the control and regulation in complex dynamic systems. The most carrying weight theories, unifying by cybernetics, are: transmission of a signal theory, management theory, automata theory, synergetics, theory of algorithms, image discrimination theory, optimal control theory, theory of learning systems. Cybernetics became a theoretical basis of computer technology.

Electronics and computer technologies in its development has gone through several generations. Each generation of electronic computing machines (ECM) differed from the previous generation in element base, speedwork, outside dimensions, volume of operational and long-term memory, interface capabilities. The first electronic digital computer (EDC) was invented in the USA in 1946. Element base of the 1st generation of ECM, which were used in the 1950s were ordinary electron tubes. Technical means of this generation ECM occupied the room equal school sports hall. Speedwork, volumes of operational and long-term memory of these ECM were small. Information in the ECM were entered using punched cards, the results of the various calculations were printed on wide paper tape. Maintenance of such ECM required significant technical staff. Element base of the 2nd generation of ECM, which are widely used in the 1960s became semiconductors. In this regard speedwork, volumes of operational and long-term memory of ECM jumped very much. ECM of this generation used high-level programming languages and the principle of library programs. Further progress in the development of ECM occurred in connection with the advent of integrated circuits, which became the basis of the ECM element base (1970-ies). They were changed by the large-scale integrated circuits, and then - very-large-scale integrated circuits (3rd, 4th, 5th and next generation ECM). A new element base allowed to create ECM with a developed configuration of external devices; to increase significantly the volumes of operational and longterm memory; to implement multiprocessing; to create an advanced operating system that provides parallelism of operations; to create advanced tools for dialogue. Speedwork of supercomputers built on modern microprocessor element base reaches tens of petaflops (quadrillions floating point operations per second, flop/s - FLoating-point Operations Per Second). Such ECM can have actually unlimited necessary operational and long-term memory. And for all the technical devices of such super ECM is a small room enough. Background information in the digital and text form can be entered into the modern ECM using the alphanumeric keyboard or scanner. The results of processing this information can be outputted from the ECU via various classes of printers (laser, inkjet) in black and white as color. This information may also be displayed on the various classes of monitors (cathode ray tubes, liquid crystal). Recent advances in microelectronics have led to the creation not only of supercomputers, but ECM and such as your personal desktop, and mobile computers - laptops and tablets, which in its capabilities exceed the ECM 2nd generation.

\section{BASIC PRINCIPLES OF PROGRAM-TARGET PLANNING AND MANAGEMENT}

The main feature of the present time is the acceleration of scientific and technical progress, which is based on the full intensive development of fundamental research in basic, promising areas of natural and technical sciences, as well as the integration of science and industry. The essence of this integration is to unite on the basis of, firstly, modern methods and, secondly, the new organizational forms of planning and management of all stages and phases of the process of creation of new technics, starting from the emergence of a scientific idea and ending with its practical implementation. This new organizational form of planning and management of the creation of new techniques is program-target planning and management. It allows the creation of new machinery, surpassing the world level in the required timescale and with minimum expense for their development, production, assimilation and exploitation.

Program-target planning and management for many years, is one of the most common and effective methods of state regulation of the economy, used in most developed countries. Among them are Canada, Japan, South Korea, Austria, Germany, France, Finland, the USA and others.

Attempts to use target-oriented approach in the national territorial planning took place as early as1920-1930. First software idea in the USSR were implemented in the GOELRO plan, developed in 1920. Issues were being resolved not just buildings of 30 regional power plants, and the whole set 
of interrelated issues: increase fuel production, improvement or creation of its processing and transportation; industrial development; training of personnel; the creation of urban infrastructure, etc. Program-target approach has also found application in the creation of the Ural-Kuznetsk Combine, the development of the Khibiny mountains, building of a large industrial center of Komsomolsk-on-Amur and others. However, the level of methodological support of program-target planning and management at the time was very low.

The use of program-target planning and management on a new methodology basis with using the latest advances in the field of operations research, cybernetics and computer technology implemented in the USA R. McNamara in the mid1960 s to planning and management of development of weapons and military equipment (WME). Under his leadership the United States Department of Defence developed and implemented a system PPBS (Planning, Programming, Budgeting System). By 1966 the Pentagon started work in a new way and the American administration set the task of such transition before other Federal agencies. Principles of program-target planning and management were used for the preparation and implementation of space, military-strategic, territorial, scientific, technical and other programs and projects. American developments have brought to the conceptual framework of the program-target approach accurate structural and logical mathematical methods of partition the general scheme of the program into separate subgoals, problems, tasks by building tree of goals based on graph theory, assessing methods of the contribution to the achievement of the general goal, that allow optimally allocate the necessary resources for all elements of the program, methods of construction of organizational and management structures of goal's implementation etc.

In 1970-1990 target complex programs were widely used in the USSR as the most important constituent parts of the state long-term plans for economic and social development.

The current Russian budget is formed on the basis of targeted programmes. There were developed 39 state target-oriented program (STP). Programs covered in $201458,5 \%$ of the budget. As an example some STP: «Federal Space Program», «Development of civil aeronautical engineering», «Development of civil marine equipment», «Development of electronic component base and radioelectronics», «Housing», «Economic development in rural areas», «Development of Education» etc. Preparations are under way to the program start «Research and development on priority development fields of science and technology sector of Russia for 20142020».

From 1970 to the present time in our country is realized program-target planning and development management of WME [1]. The necessary controls and research institutions were created, organizational procedures, mathematical methods and models were developed, as well as relevant practical experience were gained. All this can be used in the implementation of program-target planning and management in the national economy.

At the heart of the planning and management of development WME is state defense order, representing the task for delivery of goods (WME, raw materials, materials, components, military stores etc.), execution of work (research and development, elimination of chemical weapons, building activity etc.), rendering services (repair, modernization of WME etc.) for federal needs in order to ensure the defense and security of the Russian Federation. State defense order is based on the «State Armaments Programme» for 10 years, which has a hierarchical structure corresponding to the structure of the armament system of the Armed Forces of RF. On the lower level of the «State Armaments Programme» are promising complexes (samples) WME, for each of which are specified military operational requirement, cost and timing of research and development, the volume of purchases by year planning period.

It follows from the foregoing that the main instrument of program-target planning and management is a program - a long-term planning document, combining purpose and objectives on terms of their achievements with the necessary tools and resources.

Before considering the basic principles of program-target approach to the planning and management, will focus on its basic concepts [1], related to the formalization of the organizational form of human activity, including planning and management.

Goal - the desired result of activities, achievable within a certain time interval. 
Task-the desired result of activities characterized by a set of quantitative data or parameters and attainable for planned (specified) time interval $\left[\mathrm{t}_{0}\right.$, $\mathrm{t}_{1}$ ]. Usually tasks are a concretization or detailed elaboration of goals from different sight angles. In general completion period of tasks is less, than the time for achieving goals.

Since the goal emerges as a more general category than the task, then we can assume that the goal is achieved by solving a number of tasks in connection with this problem can be ordered in relation to the goals.

Problem - a potential target (task), for which or is still not found an alternative to achieve it (the decision), or it is not possible to allocate resources to the search for alternatives and conducting an operation to achieve it (the decision), or both together.

Obviously in any sphere of activity are always more than can be goals and objectives. Analyzed and evaluated competing options to achieve a goal or solve the problem called alternatives of action or just alternatives.

A sequence of increasingly sophisticated in any sense of the goals we will call direction of development.

Operation - activity of the team, managed from a single center and aimed at achieving a goal or solution to the problem. Governing body of the operation has the ability to distribute the operation in accordance with the plan of operation all dedicated to the operation financial, human and material resources.

By the nature of behaviour there are two types of operations: terminal and continuing or developing.

Terminal operations ends the achievement of this goal finite time interval $T$, after which the resources can be used in other operations. Terminal operations include the creation of complex technical systems (CTS), human-machine systems (HMS), construction of facilities, buildings, new businesses, activities on disaster clean-up operations, etc. Terminal operations can form a sequence when the previous operation creates the preconditions for the implementation of the following with a more perfect in any sense of purpose, for example, the sequence of operations for space exploration (satellite launching, Laika in space, launching a man into space, long-distance flight of a man-in-space, joint flight of spacecrew, launching a man to the Moon, space-vehicle launching to Venus and Mars).

Developing operations - mass, serial production of goods and services, trade, learning processes in schools and universities, and so on. In this case, the goal of operations are periodically repeated for each year, quarter, month. The goals from period to period are becoming more and more perfect from any point of view. Thus, the developing operation associated with the implementation of the directions of development.

The results and timing of operations are usually probabilistic in nature. The operations aimed at achieving thegoals, have agreater degree of uncertainty than operations, associated with the decision task. Any large scale operation can be represented as a multilevel hierarchical set of operations on a smaller scale. Moreover, the partitioning of operations is being done according the partitioning of the goal's (task) operation on a hierarchical set of sub-goals (sub-tasks). The partitioning is done to the level of tasks that are easy to take for elementary, i.e. those which are characterized by the only sustainable having no alternative method of solution.

Management and leadership of the governing body of the operation is called a sequence of commands, orders, signals, etc., that lead to a particular method of use or distribution of human and material resources, machinery, equipment, raw materials throughout the operation.

When managing the operation (activity) five successive steps take place: statement of goal; making a decision - a choice the best among many possible alternatives in accordance with the selected criterion (target function) [2, 3]; execution of the decision - the operation (operational control) and obtain the desired results; evaluation of results; recommendations for the future, which focuses mainly on improving the planning and operational management process.

Work - procedure, the result of which is material in nature, associated with the transformation of materials, energy, transportation of materials etc.

Work $x=(a, b, T)$ is characterized by: - parameters vector $a=\left(a_{1}, a_{2}, \ldots\right)$, that determine the result of the work;

- resources vectorb $=\left(b_{1}, b_{2}, \ldots\right)$, equired to perform the work;

- time $T$, released to perform the work.

If the operation is to achieve a goal of large- 
scale long enough, a plan of such an operation is called a program. In other words, the program - a comprehensive plan for a large-scale continuous operation. Or more precisely program - it is a comprehensive plan for long-term collective activities aimed at achieving the goal of large-scale or for the implementation of directions development.

In accordance with certain kinds of operations we have the types of programs too: terminal (the program «Apollo», programs for the construction of the Bratsk and Tyumen territorial industrial complexes, KAMAZ, BAM, etc.) and developing (development of the world's oceans, the energy of thermonuclear reactions, development of Nonchernozem zone, etc.).

The difference between the program and the long-term plan is that the program is focused on one goal, and long-term plan - on the department or organization whose activities are multi-purpose in nature. Long-term plan is formed from fragments of programs, the implementation of which involved the department or organization. In addition, longterm plan of some department or organization is multifunctional, i.e. consists of the individual plans, as the production plan, plan logistics, plan for labor and wages, financial plan, plan of capital construction, research and technological development plans etc.

In contrast to all of the functional plans the program has complex character, i.e. contains the full range of activities (works) to achieve the same goal or implementation of development directions. Therefore, the above definition of the program can

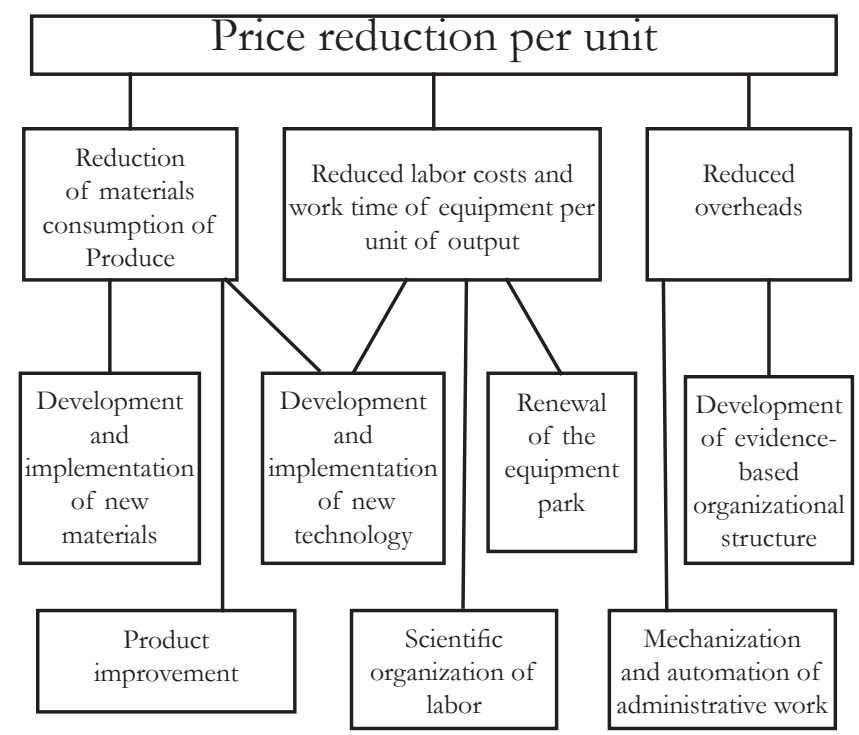

Fig. 1. Structure of the program to reduce cost-per-unit in the industry sector or the company. be clarified.

Program - a long-term planning document, which contains a detailed over time, balanced on resources, compatible on executors and timing of the implementation, full set of socio-economic, organizational, economic, production, design, research and other activities aimed at achieving one goal or the implementation of development directions. The balance of resources means that there are no tasks, that are not resourced and that optimal from any point of view distribution of limited resources among the governing bodies of lower rank was conducted.

Implementation of the operation or implementation of the program can be shown by three types of graph-schemes or models.

1) Development of programs begins with the construction of the graph goals and tasks, which bears a name of structure of the program. The system of goals is hierarchical in nature due the fact that the overall goal of the operation is achieved only by the implementation of a hierarchical set of private operations of various ranks. In compiling the structure of the program is useful to set the weights $p_{j}^{i}$ of goal's importance $j$ inside each level $i$, for which there exist special methods. As a concrete example Fig. 1 shows a three-level structure of the program to reduce the cost-per-unit in the industry sector or the company, which shows that the goals of of the lower level are the means (ways) to achieve the goals of the upper level.

2) The next graph-scheme - information model, which reflects the hierarchical structure of the organizational system that implements a given program, showing all the material and information flow between governments for various services, departments, production units etc.

3) And finally - the network model (Fig. 2), which gives an idea about the implementation of

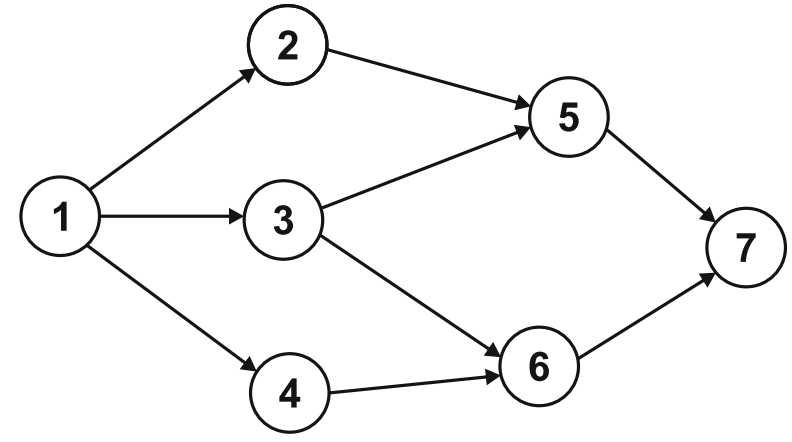

Fig. 2. Network model. 
the program over time, reflecting the process of implementing a set of interrelated activities aimed at achieving the ultimate goal, and also allows to determine the importance of these characteristics of the considered process, its duration, complexity, cost, etc., based on accounting values of the relevant characteristics of individual works and the relationships between them $[1,4]$.

Programs to achieve certain goals, usually thought to sliding, i.e. with periodic adjustments, which gives them an adaptive character.

In the structure of any scientific and technical program physically exist only complex technical and human-machine system (CTS, HMS). They ultimately determine the correctness of the taken decisions. Other higher levels are to some extent of conditional nature and their construction is necessary in the interests of further study plans of higher level.

In the process of scientific and technological progress is a change of some samples CTS (HMS) to others, more sophisticated. Consequently, one of the main and priority tasks of accelerating the pace of scientific and technological progress is the use of program-target planning and management of the establishment of CTS (HMS) to reduce the length of time from the appearance of a scientific idea to its wide practical implementation, and optimization of material, financial and human resources involved in this process.

\section{END-TO-END PLANNING AND MANAGEMENT OF THE CREATION OF CTS (HMS)}

Change one sample of CTS, HMS to the other, new lets talk about the life cycle of the sample CTS (HMS), about its birth and dying, i.e. decommissioning.

The life cycle (Fig. 3, LC) of some CTS or HMS, as usual, consists of the following stages or steps:
1) Study intention. At this stage, ideas on the implementation of the latest achievements of science and technology are born for meeting of CTS to the growing demands. There are determined desired operational and physical characteristics of perspective CTS, possible ways of its creation, are established the need for new technical solutions from the analysis of the tree structure CTS (Fig. 4) and the conditions for the realization of this tree. The result of the ending of stady intention is a technical task for realization of appropriate target research works (RW) indicating their purpose, timing, interaction of research institutions in conducting research.

2) Realization of appropriatetarget $R W$-fundamental, search and applied. One determines the ability to use particular scientific advances to improve the efficiency of the CTS, possible principles creation and establishing a new CTS are reviewed.

3) Development of technical proposals or preliminary design. From the analysis of possible options for a new CTS one determines the optimal way of its development, implementation and evaluation of the timing of realization and costs for all subsequent stages of LC. You must have some competitive technical proposals, if not the whole CTS, then at least its major subsystems, to choose the optimal way of developmental work at the stage of development of technical proposals. Competitive technical proposals usually are developed in parallel by different research and development organizations. If necessary, at the stage of development of technical proposals can be carried out more targeted research.

4) Developmental work $(D W)$. There are consistently developed conceptual, technical and working projects, the requirements for which are determined by the all-Union State Standard. The result is a working design documentation for production, assembly and erection of CTS, as well as the operation and maintenance documentation

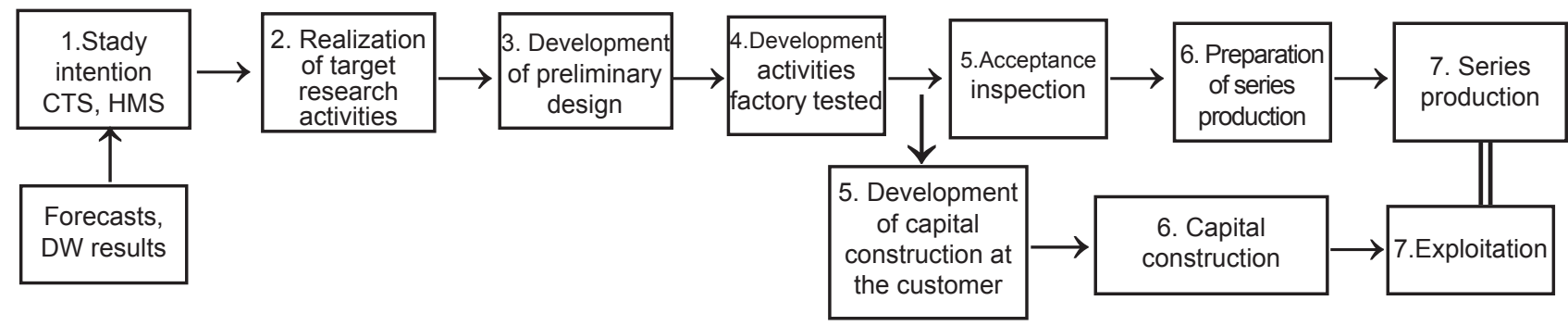

Fig. 3. Life cycle CTS (HMS). 


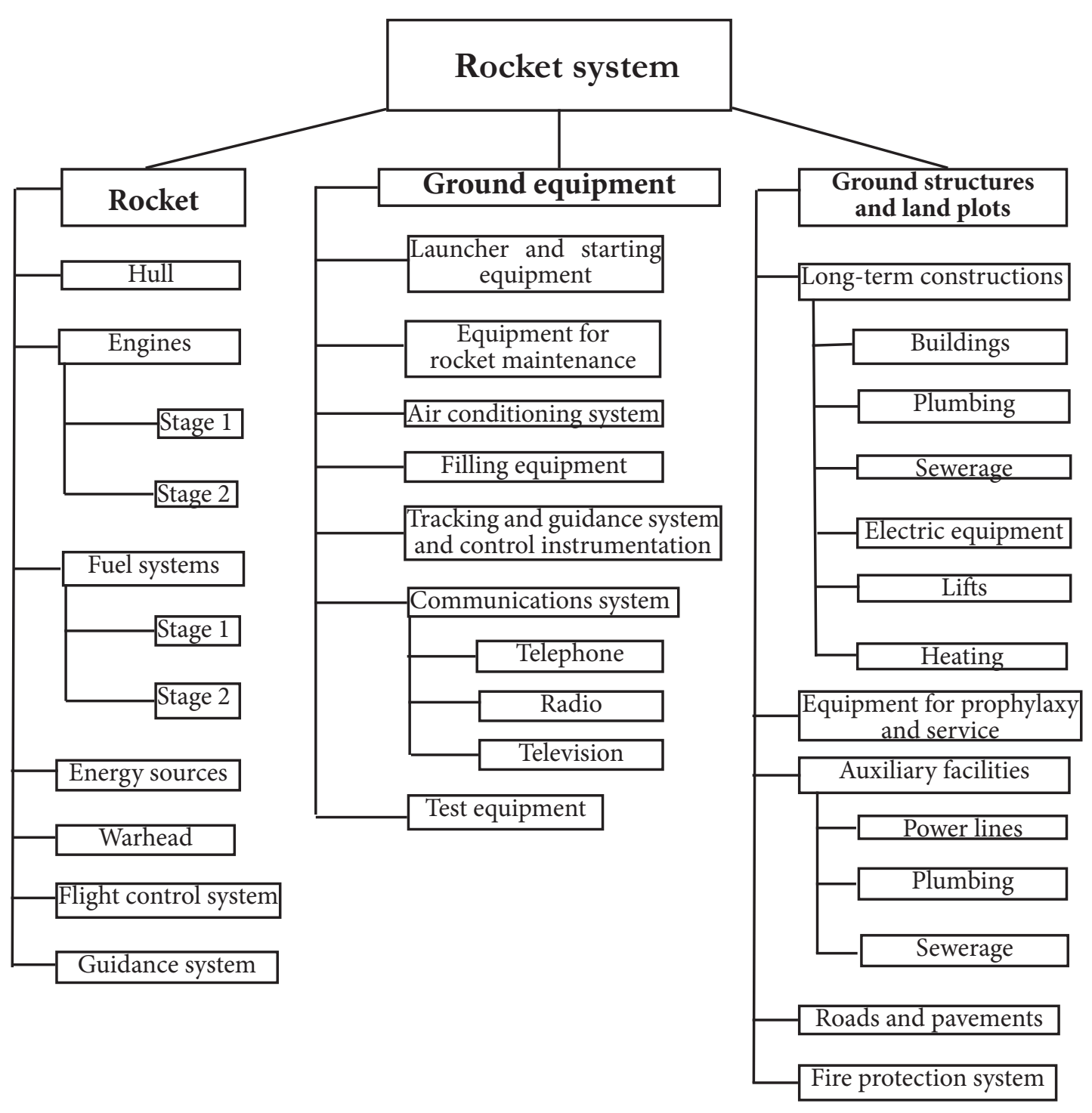

Fig. 4. Tree structure rocket system.

of CTS. This stage also includes the creation and of CTS (HMS).

production tests of the prototype CTS to test its performance, pre-checking the conformity of its basic parameters and requirements specification of design documentation.

5) Acceptance inspection. There are determined the CTS according to the technical task, the possibility of putting it into serial production. Simultaneously with the acceptance tests should be developed by the capital construction project for the customer.

6) Productionisation and capital construction of objects at the customer. Developing new production methods, tools, jigs and fixtures.

7) Serial production and exploitation. Part LC CTS (HMS) from elaboration of the plan to serial production is called the Implementation Period, and from the start of series production to decommissioning is called the period of useful life
The main direction of improving the planning and management of the creation of CTS (HMS) is end-to-end planning and management of their life cycle, the essence of which is that the whole cycle of «research - production» is treated as a single process aimed at achieving the ultimate goal. End-to-end planning and management let reduce implementation period of CTS by eliminating gaps between the individual stages of LC, as well as the parallel execution of some works related to the different stages.

Individual stages of LC CTS can be characterized by level of costs $C$, necessary for their implementation. It should be noted that the uncertainties $H$ in obtaining the desired results are very large in the early stages of LC and fall as far as 


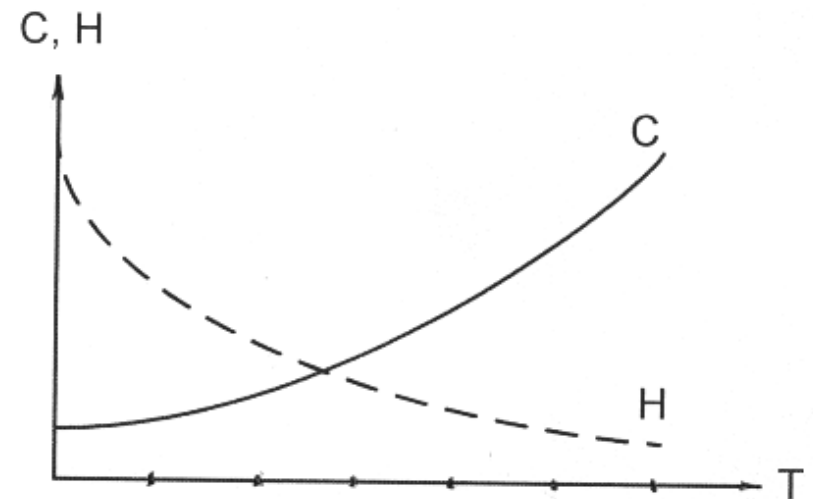

Fig. 5. Level of costs.

creating of CTS (Fig. 5). On the other hand, price of the work $\mathrm{C}$, is relatively low in the early stages of LC of a new CTS, increases as the transition to later stages. Therefore, spending relatively little money on the early stages of LC, we significantly reduce the degree of uncertainty in the successful completion of the development and avoid large overhead costs that may arise in connection with setbacks and alterations in the stages of DW, testing and serial production.

The process of creating CTS (HMS) in view of their complexity, typically represent long-term operation. To implement end-to-end planning and management of the holding of each such operation must be preceded by the development of an appropriate program for creating CTS (HMS). In the initial stages of the life cycle CTS (HMS) to DW project, when the uncertainties in achieving the ultimate goals are great, this program is called the target forecast. As the reduction of uncertainties in the process of creating CTS (HMS) on the basis of the forecast target lifecycle is developed end to end plan of CTS (HMS).

The target forecast of CTS (HMS) lifecycle is a probabilistic judgment about the process of its creation. In the target forecast of lifecycle CTS (HMS) should be considered alternatives to achieve the ultimate goal for each of these options are set the expected cost of resources and time. The information contained in the target forecast of lifecycle CTS (HMS), has an orienting character. It is necessary to ensure focus during the early stages of the life cycle CTS (HMS).

In contrast to the target forecast end to end plan CTS (HMS), which covers all work on the creation of CTS (HMS), starting with $\mathrm{R} \& \mathrm{~d}$, has prescriptive character. It should contain only one best option of creating CTS (HMS) showing all the data on the CTS
(HMS), the timing of creating CTS (HMS) and the necessary resources. End to end plans of CTS (HMS) provide a basis for quantitative calculations in the preparation of planning documents all higher levels and must contain the following required data: the purpose of CTS (HMS), its main characteristics, the timing of execution of certain works, information about the performers, the cost distribution by years, the volume of capital construction, the timing and volume of deliveries, as well as a comprehensive network model. As the proceeds set of interrelated works on the development, testing and production of CTS (HMS), as well as of capital construction end to end plan should be updated periodically as a result of the phase of decision-making [2].

When end to end planning and management of creation of CTS (HMS) in their life cycle disappears such lightly managed category as the introduction of scientific and technological achievements. Reification of knowledge will have planning character.

\section{DECISION-MAKING WHEN END-TO- END PLANNING AND MANAGEMENT OF THE CREATION OF CTS (HMS)}

The main point of the end to end planning and management of creation of CTS is decisionmaking. The essence of the decision-making is to compare several alternatives of action and selecting the best of them in accordance with the indicators. With various alternatives of action are associated different probabilities of success, and costs of various kinds of resources and time. These probabilities and costs can not always be accurately determined.

Depending on the availability of initial information solutions for end to end planning and management of creation of CTS may be taken in conditions of risk or certainty.

If for each alternative is known to what the final result it will bring, as well as the known amount of time and resources, the decision is made under certainty.

If for each alternative are known possible end result and the probability of its achievements as well as the probabilistic characteristics of time and resources, then we say that the decision is made under risk.

Uncertainties, which should be overcome when end to end planning and management of creation of CTS, can be divided into two groups - external and internal. 
External uncertainties - uncertainties in the assessment of the true needs of CTS, as well as in the assessment of development environment, science, technology and economy, excluding the possibility a strict tasking of CTS creating in the early stages of LC. When deciding on the development of CTS these uncertainties will not be properly evaluated, it may be that the developing CTS will be ineffective or useless. As a result significant resources are lost, and most importantly - the time, the loss of which can not be recovered.

A major role in the assessment of external uncertainties in the end to end planning and management of creation of CTS should play a permanent system of military-political, demographic, scientific, technical and economic forecasting. On the basis of the forecast information provided by these systems, it is possible to correctly formulate the ultimate goal of CTS and get an estimate of its required amount.

Among the internal uncertainties of creation of CTS are technical and economic uncertainties.

Technical uncertainties associated with the assessment of opportunities and ways to create CTS with given specifications. These uncertainties are generated by the ambiguity of the structure of CTS. Multivariance structure of CTS in turn is caused by a variety of types of component elements and their parameters. Incorrect assessment of the technical uncertainties may result in termination of the development of CTS due to impracticability of initial requirements to it.

Overcoming technical uncertainties should be based on the use of various types of system descriptions of CTS, each of which represents a certain model of CTS, reflecting certain aspects of its construction and operation. The variety of system descriptions CTS can be reduced to four main: macroscopic, parametric, functional and morphological. The methodology for constructing these descriptions is given in the publication [5].

Economic uncertainties associated with the assessment of the duration of the individual stages of the LC and the costs of implementation.

Of great importance when deciding on the creation of advanced CTS plays the accuracy of determining the duration of implementation period. If the assessment specified duration will be too low compared to the actual, it can cause that created CTS will go into operation when it is already outmoded. In the best case the reduction in the duration of Implementation Period may result in termination of the development of the new CTS. It is very difficult to obtain a reliable estimate of the duration of the implementation period at the initial stages of LC CTS (study design, conducting targeted research). Often the error when estimating the duration of the implementation period until the beginning of the DW project are [1] from 2 to 5 years to decrease this duration.

It is difficult in the early stages of the LC also to give a reliable estimate of the total cost of creating of CTS. The cost is also usually underestimated The degree of divergence of the actual and estimated cost is directly related to the extent of scientific and technological change, embodied in the created CTS. If the CTS requires major technological shift, the error in the cost estimate are large, it is often the ratio of actual cost to estimated may reach 4 . In that case, when a small scientific and technological shift is needed, the ratio is $1.1-2.0$ [1]. These values can be used as constant factors in the calculation of the total cost of creating of CTS in the early stages of LC. Undertake a study also shown that estimates the cost of the work (activities, operations, actions) and necessary for their implementation time become more precise as we move from one stage LC CTS to another.

Thus, the uncertainties in the source data - an objective property of the environment in which decisions had to be made when the end to end planning and management of creation of CTS. It can be concluded about inexpediency of making a final decision on the establishment of some CTS if it is on one of the initial stages of LC. This means that after the completion of each stage of the LC should take a new decision on continuation of works on creation of CTS, and all the early decisions lose their effect if they do not coincide with the latter.

In consequence of reducing of uncertainties as we move from one stage LC to another decisions are taken when the end to end planning and management of creation of CTS after completion of the initial stages of LC under risk, after completion of the DW project and factory testing decisions are taken usually under certainty.

Decision to continue the work for creation of CTS after the completion of each regular stage LC should be taken at least on the following parameters: 
$W$ - effectiveness of CTS; $P_{t c h}$ - the probability of creating of CTS with given specifications; $C_{\mathrm{rp}}-$ cost of the remainder of the Implementation Period, to be able to start serial production of CTS; $C_{\text {sf }}$ cost of the serial production of CTS; $C_{\mathrm{e}}-$ full cost of operation CTS in a unit of time (year, month, day); $T_{\mathrm{e}}$ - time of receipt of the CTS in operation; $T_{\mathrm{ul}}$ duration of the period of useful life of CTS.

Let us examine briefly each of these indicators.

Obviously, CTS should first of all meets the specified requirements for efficiency $W_{\mathrm{e}}$, i.e. the condition must be satisfied $W \geq W_{\mathrm{e}}$. In the initial stages of LC, when the possibility of full-scale experiments is virtually eliminated, the value of the efficiency index $W$ for each option of CTS can only be determined by a mathematical model of its operation or application that also allows to get depending on characterizing the influence of the structure and parameters of the CTS, nature of the relationship between the subsystems on its effectiveness for a given impact of the environment.

In practice, very often with the help of mathematical modeling is necessary to evaluate the effectiveness of different options CTS is not on one, but on several parameters. This may be due that in some cases creating CTS are multi-purpose, i.e. designed to solve a number of problems. The choice of the optimal variant of the CTS on two or more indicators in a rigorous mathematical statement is impossible, because any option, which is the optimal one performance indicator, as a rule, is not optimal for other indicators. In this case, it may be a compromise solution: preference is given to option, which, while not the best on any indicator, is acceptable in several indicators, i.e. rational variants of CTS are found and one of them is selected.

With the help of mathematical modeling operation (application) CTS assessment of its various options can be carried out not only in terms of efficiency, but also in terms of other properties: reliability, stability, noise immunity, etc. In this case, obviously, it is important that these properties were taken into account in the structure of the mathematical model.

Because of technical uncertainties exclude the possibility of selection after study design a single CTS creation's option, it is necessary to consider a wide range of alternatives and select the most probable of them as we move from one stage LC to another. On the basis of generalization of a number of research works $[1,2]$ it is possible to recommend the following target values of the indicator $P_{\text {tch }}$ for selecting options for a new CTS after the appropriate stage of LC: development plan - 0.1-0.6; conducting of targeted research - 0.5-0.8; development of technical proposals - 0.7-0.95; DW project - 0.91.0; testing, capital construction, preparation of serial production - 1.0. Lower statutory value of the index $P_{\text {tch }}$ consistent with CTS, the creation of which requires major technological shift, upper CTS, which need a small scientific-technical shift. If for some options for creating a CTS is received, the station reserve fuel facility index value is less than the standard, this option is eliminated from consideration.

The essence of the use of indicators $C_{\mathrm{rp}}, C_{\mathrm{sf}}$ and $C_{\mathrm{e}}$ is quite simple and is as follows. The calculated values of indicators of $C_{\mathrm{rp}}$ and $C_{\mathrm{sf}}$ must not exceed respectively allocations for research, development and production of CTS. Otherwise, the decision must be made for an additional appropriation or termination of the work on the creation of a new CTS. The value of the $C_{\mathrm{e}}$ is used when choosing one option from a number of possible equivalent on other indicators of CTS options. Preference is given to that option, which is cheaper to operate. The accuracy of determining the values of indicators $C_{\mathrm{rp}}, C_{\mathrm{sf}}$ and $C_{\mathrm{e}}$ is low at the initial stages of LC CTS and is growing rapidly as we move from one stage to another.

The indicator $T_{\mathrm{e}}$ determines the time of receipt of CNS in operation. The value of the indicator $T_{\mathrm{e}}$ should not exceed the set time $T_{\mathrm{e}}$ for creation a new CTS. The value Te is easy to identify, if known, the duration of the remaining part of the implementation period of CTS.

And finally, a big factor in the decision to continue the work on the creation CTS plays duration of the useful life of $T_{\mathrm{ul}}$. If it is too small, the feasibility of creation of CTS can be questioned. In assessing $T_{\text {ul }}$ of creating CTS it is necessary to consider trends in the development of the type of equipment to which it relates, the development prospects of competing types of CTS and other factors. It should be noted that in each case the list of these indicators can be extended (the impact of 
the new CTS on the development prospects of other CTS, extent of use when creating CTS of the latest achievements of science and technology in all design and technological solutions, etc.).

For each option of CTS value determination $P_{\text {tch }}$, the amount of work at each stage of LC, the timing of the individual steps, costs by stages can be carried out using a network model with deterministic and stochastic structure $[1,7,8]$, which allows implementation of display processes set of interrelated works for creation of CTS. Knowing these figures is quite easy to obtain and values of $C_{\mathrm{rp}}$ and $T_{\text {e }}$.

The cost of serial production $C_{\mathrm{sp}}$, the full cost of operation of the $C_{\mathrm{e}}$ and the duration of the period of useful life $T_{\mathrm{ul}}$ CTS in the early stages of LC, prior to DW, can only be determined by the methods of scientific, technical and techno-economic forecasting. At stages of DW and testing the value of $C_{\text {sf }}$ can be determined under calculation, i.e. for each $i$-nd subsystem CTS finding costs expenditures connected with: basic materials $C_{\mathrm{bm}, \mathrm{i}}$, ready furnished parts $C_{\mathrm{fg}, \mathrm{i}}$, compensation $C_{\mathrm{p}, \mathrm{i}}$, overhead costs $C_{\mathrm{o}, \mathrm{p}}$ damage of defects $C_{\mathrm{d}, \mathrm{i}}$. As a result of summation of cost expenses on articles you can find the cost of serial production of CTS:

$$
C_{s f}=\sum_{i=1}^{k}\left(C_{b m, i}+C_{f g, i}+C_{p, i}+C_{o, i}+C_{d, i}\right),
$$

where $k$ - number of subsystems CTS.

When forecasting or calculation of the total cost of of operating a single sample of CTS must be borne in mind that the value of $C_{\mathrm{e}}$ includes direct operating costs $C_{\mathrm{dc}}$, related to the functioning of the CTS, storage costs $C_{k}$ and the cost of maintaining staff $C_{\mathrm{s}}$ :

$$
C_{\mathrm{e}} \stackrel{\mathrm{s}}{=} C_{\mathrm{dc}}+C_{\mathrm{k}}+C_{\mathrm{s}} \text {. }
$$

The value of $C_{\mathrm{dc}}$ includes the cost of technical support (all types of servicing, repairs, supply of spare parts), the cost of fuel and lubricants, the cost of maintenance of structures. The value of $C_{k}$ consists of the cost of maintaining of resource base and costs of all kinds of works in storage CTS. The value of $C_{\mathrm{s}}$ includes salaries of staff, as well as the construction costs of residential buildings, etc.

Following the development of the technical proposals of the competing options of CTS, that meet all the above indicators, you need to choose one according on the criterion «costs - effectiveness». When choosing the optimal variant of CTS on this criterion of the three indicators $W, C$ and $T_{\mathrm{e}}$ one is accepted as the main, and the other two are put into constraints. Here $C$ - total price.

Following the development of technical proposals, and at all subsequent stages of the LC of those competing versions of the CTS that meet all the above indicators, you need to choose one according to the criterion of «costs - effectiveness». When choosing the optimal variant of CTS on this criterion of the three indicators $W, C$ and $T_{\mathrm{e}}$ one is accepted as the main, and the other two are put into constraints. Here $C$ - total price, which is defined as follows:

$$
C=C_{\mathrm{rp}}+n C_{\mathrm{sf}}+n C_{\mathrm{e}},
$$

where $n-$ the value of the series.

Most often as the main indicator are taken effectiveness or cost. In the first case the task takes the meaning of optimization of CTS. Mathematically it is formulated as follows:

$$
W \rightarrow \max , C \leq \hat{C}, T_{\mathrm{e}} \leq T_{\mathrm{ee}}
$$

where $\hat{C}$ - a given limit value, the total cost of $C$.

In the second case the task takes the meaning of optimization of the allocation of resources and has the form:

$$
C \rightarrow \min , W \geq W_{\mathrm{e}}, T_{\mathrm{e}} \leq T_{\mathrm{ee}} .
$$

However, in some critical situations in the first place there is the time of being of the new CTS in operation. The mathematical formulation of this problem has the form:

$$
T_{\mathrm{e}} \rightarrow \min , W \geq W_{\mathrm{e}}, C \leq \hat{C} \text {. }
$$

Since the establishment and functioning of CTS occurs in conditions of a large number of uncertainties or actions of a large number of random factors, then these indicators should be treated as random variables, which can be characterized by the laws of their distribution or other probabilistic characteristics. When deciding on the further continuation of works on creation of CTS after the next stage of LC (up to DW inclusive) as indicators of $C_{\mathrm{rp}}, C_{\mathrm{sp}}, C_{\mathrm{e}}, T_{\mathrm{e}}$ and $T_{\mathrm{ul}}$ are choosing their average values (mathematical expectations). In assessing the effectiveness of CTS, if the result of its operation is a random event, as an indicator of the effectiveness of $W$ is selected probability of accomplishment of this event. If the result of the functioning of CTS is some random variable, as an indicator of the efficiency of $W$ take the average value (mathematical expectation) of value. 


\section{CONCLUSION}

The constant growth of socio-economic development of our country in the world today can provide only an accelerated transition to the highquality production. The solution to this problem can be carried out on the basis of program-target planning and management creation of new machinery, with or surpassing the world level, in the required timescale and with minimum expense for their development, production, assimilation and exploitation. Programtarget planning and management is one of the most common and effective methods of state regulation of the economy. Its main principle is end-to-end planning and management of the creation of CTS (HMS) along its life cycle to reduce the length of time from the appearance of a scientific idea to its practical implementation and optimization of material, financial and human resources involved in this process. This article should allow a deeper understanding of the main provisions of the program-target planning and management and to use them in practical activity.

\section{REFERENCES}

1. Morse FM, Kimball GE. Methods of Operations Research. New York, Cambridge, MA, Technology Press of MIT, 1951, 158 p.

2. Pospelov GS, Barishpolets VA Novikov LS. Program-targeted planning and managing the creation of military equipment. Moscow, NTC Informatika Publ., 1990, 407 p.

3. Barishpolets VA. Justification of solutions with end-to-end planning and management of the creation complex technical (human-machine) systems. Coll. «Modelirovanie, dekompozitsiya $i$ optimizatsiya slozhnykh dinamicheskikh processov [Modeling, decomposition and optimization of complex dynamic processes]», pp. 91-106. Moscow, Computing centre of RAS Publ., 2010 (in Russ.).

4. Barishpolets VA. Modeling of the process of creation of complex, technical or humanmachine system in a conflict situation. Coll. «Modelirovanie, dekompozitsiya $i$ optimizatsiya slozhnykh dinamicheskikh processov [Modeling, decomposition and optimization of complex dynamic processes]», pp. 79-86. Moscow, Computing center of RAS Publ., 2012 (in Russ.).
5. Osnownye polozheniya po razrabotke $i$ primeneniyn sistemy setevogo planirovaniya $i$ upravleniya [General provisions for the development and implementation of the system of network planning and management]. Moscow, Ekonomika Publ., 1965, 197 p.

6. Barishpolets VA. Methodology of systematic description of complex technical (humanmachine) system. Coll. «Modelirovanie, dekompozitsiya $i$ optimizatsiya slozhnykh dinamicheskikh processov [Modeling, decomposition and optimization of complex dynamic processes]», pp. 68-87. Moscow, Computing centre of RAS Publ., 2011 (in Russ.).

7. Sargsyan SA, Akhundov VM, Minaev ES. Bolshie tekhnicheskie sistemy: analiz i prognoz razvitiya [Large technical systems: analysis and forecast]. Moscow, Nauka Publ., 1977, 386 p.

8. Philips DT, Garcia-Diaz A. Methods of network analysis. Moscow, Mir Publ., 1984, 312 p.

9. Barishpolets VA. Method of constructing a network model with a stochastic structure. Coll. «Modelirovanie, dekompozitsiya i optimizatsiya slozhnykh dinamicheskikh processov [Modeling, decomposition and optimization of complex dynamic processes]», pp. 68-85. Moscow, Computing centre of RAS Publ., 2007 (in Russ.). 